\title{
NOTAS SOBRE AS ENTREVISTAS COM PROFESSORES DE UMA ESCOLA PRIVADA E OUTRA PÚBLICA DO MUNICÍPIO DE CAMPO GRANDE - MS
}

\author{
Branca Maria de Meneses \\ Dulce Regina dos Santos Pedrossian \\ FERNANDA RITA LEVANDOSKI \\ Universidade Federal de Mato Grosso do Sul (UFMS), Campo \\ Grande, Mato Grosso do Sul, Brasil
}

Resumo: Neste artigo, apresentamos dados das entrevistas realizadas com seis professores (três de uma escola privada e três de uma pública) do município de Campo Grande - MS, que ministram as disciplinas Língua Portuguesa, Educação Física e Artes, conforme roteiro constante no projeto Violência escolar: discriminação, bullying e responsabilidade (CROCHÍK, 2014), com acréscimo de duas questões. Expomos a compreensão dos professores em relação ao bullying e à educação inclusiva; à identificação e aos motivos do bullying na escola; às características dos agressores e dos agredidos; aos alunos considerados em situação de inclusão serem alvo de bullying tanto quanto os outros; e sobre o que é necessário para combater esse tipo de violência na escola e acerca do papel das autoridades. Concluímos que cabe propiciarmos uma educação que se direcione para formar cidadãos conscientes de seus direitos e deveres, que respeitem as diferenças e reflitam sobre os valores democráticos cotidianamente suscitados com vistas ao bem comum.

Palavras-chave: Bullying. Educação inclusiva. Discriminação. Bem comum. 
Neste artigo, expomos parte dos resultados da pesquisa - que faz parte do projeto Violência escolar: discriminação, bullying e responsabilidade (CROCHÍK, 2014) - realizada em duas escolas do município de Campo Grande - MS. A escola privada onde foi realizado o estudo está localizada na região central, iniciou suas atividades em 1982 e é coordenada por uma fundação de ensino sem fins lucrativos. Já a escola pública municipal foi inaugurada em 13 de fevereiro de 1998 e localiza-se na região que compreende a maior concentração de famílias cadastradas no Cadastro Único de Programas Sociais do Governo Federal (CADÚNICO).

Embora não fosse nosso objetivo averiguar por meio das entrevistas realizadas o nível de consciência dos seis professores (três da privada e três da pública) em relação ao bullying, de acordo com Silva, Freller, Alves e Saito (2017), o grau de consciência do docente e sua ulterior capacidade de autorreflexão conservam-se como mediadores importantes para que a relação entre eles e os jovens fomente o fortalecimento da racionalidade.

As professoras de Língua Portuguesa e de Artes da escola privada têm 23 e 44 anos, respectivamente. Enquanto a primeira atua na escola há três anos, a segunda exerce suas atividades nessa escola há cinco anos. Já o professor de Educação Física tem 30 anos e ministra essa disciplina há cinco anos na escola. Quanto à escola pública, a professora de Língua Portuguesa tem 33 anos e atua na escola há seis anos; o de Educação Física tem 38 anos e leciona nessa escola há sete anos e seis meses, e a de Artes tem 56 anos e exerce suas atividades na escola há nove anos. As entrevistas seguiram o roteiro constante do mencionado projeto, com o acréscimo de duas questões. Na primeira parte deste escrito, expomos a compreensão dos professores das duas escolas a respeito do bullying e da educação inclusiva; da identificação de casos de bullying na escola; dos motivos do bullying e características dos agressores e dos agredidos; de os alunos considerados em situação de inclusão serem alvo de bullying tanto quanto os outros; e do que é necessário para combater esse tipo de violência na escola e o papel das autoridades. Em seguida, procuramos refletir acerca dos argumentos apresentados pelos professores e, por fim, apresentamos nossas breves considerações.

\section{Argumentos dos professores entrevistados}

No que se refere à compreensão do bullying, para a professora de Língua Portuguesa da escola privada, esse fenômeno consiste em um tipo de exclusão que provoca ofensas de forma direta ou indiretamente. A forma direta dá-se mediante apelidos pejorativos e, indiretamente, por meio de exclusão social. Ocorre não somente na escola, mas também na família, no 
trabalho e em diversos círculos sociais; revela-se por meio de agressões físicas e, geralmente, implica relações de poder e de inferioridade, argumento este corroborado pelo professor de Educação Física dessa escola, ao compreender o bullying como um modo insistente de o sujeito demonstrar superioridade em relação ao outro e empregar violência verbal e, às vezes, física, porque a vítima apresenta alguma característica que o agressor não aceita.

A professora de Artes atribuiu a raiz desse fenômeno à família, por conta da falta de afeto, de contato físico e de segurança por parte dos pais que trabalham fora. Associou o bullying à geração nova, geração "sai pra lá", irresponsável, atual; disse que sofreu bullying pelo fato de ter sido gorda e muito magra, e questionou como seria a geração hodierna daqui a 30 anos. Quanto à escola pública, para a professora de Língua Portuguesa, o bullying é visto como brincadeira, mas compreende que são atitudes verbais ou físicas que agridem o outro e, comumente, acontecem mais de uma vez com a mesma pessoa e em grupos de crianças e adolescentes. Já o professor de Educação Física dessa escola compreendeu esse fenômeno como uma forma de discriminação, bem como citou a ofensa e o deboche como formas de agressão. Disse que os professores percebem a gravidade do problema, mas os alunos não têm consciência disso porque são menores de idade e não refletem sobre as consequências que o bullying pode acarretar. A professora de Artes dessa escola entendeu o bullying como forma de ofensa, de "tirar sarro"; quem recebe a ofensa percebe isso como uma forma de brincadeira e não leva em consideração o fato de ficar constrangido, de se fechar; ao guardar a ofensa para si mesmo, acaba por adoecer.

No que se refere à compreensão acerca da educação inclusiva, para a professora de Língua Portuguesa da escola privada, esse tipo de educação vem se fortalecendo no decurso dos anos. Os pais não vêm priorizando o cuidado dos filhos devido às exigências da sociedade atual, em que o ter se sobrepõe ao ser. Se anteriormente havia relação bem estabelecida entre pais e professores, atualmente não existe; os pais, quando realizam o acompanhamento educativo dos filhos, não reconhecem suas dificuldades e preferem atribuir a responsabilidade ao professor. As crianças, por conseguinte, desejam um professor que se envolva não somente na vida educativa, mas também pessoal.

Mesmo que a nova geração de professores venha sendo formada para cuidar da vida pessoal do aluno, até para mantê-lo "equilibrado" e, assim, poder dar aula, vem presenciando colegas que colocam alunos em situação de inferioridade por meio do jargão "eu ensino, ele aprende". Revelou descontentamento quanto a diversos aspectos relacionados à relação 
professor-aluno, como situação de sobrecarga e acúmulo de funções por parte do professor; práticas educativas traumatizantes em relação a disciplinas de exatas; conflitos de hierarquia professor-aluno; obscura delimitação de papéis entre professor e familiares; e responsabilização da família. Compreendeu ser o professor peça fundamental na "educação moral", mas que precisa também trazer algo novo, pois os alunos querem maior dinamismo durante as aulas. Já o professor de Educação Física disse que a escola tem o papel de realizar a inclusão dos alunos com necessidades especiais e com problemas no ambiente escolar, e, para isso, os professores e as escolas devem estar preparados. Tal qual a professora de Língua Portuguesa dessa escola, a professora de Artes considerou os efeitos da sociedade contemporânea em que o ter tem precedência sobre o ser. Qualificou a educação inclusiva como boa, mas em alguns momentos não, e, recorrentemente, empregou em seu discurso expressões como "sociedade normal", "psique normal", "criança normal", "criança diferente":

É boa porque insere esse indivíduo na sociedade normal. Porém tem alguns que não conseguem acompanhar. E aí, muitas vezes acaba desencadeando o bullying, muitas vezes a criança com a psique normal tem dificuldade para entender o aluno diferente. Acredito que seja importante trabalhar com a criança dita normal, pois às vezes essa criança também não é trabalhada para aceitar o aluno diferente.

A professora de Língua Portuguesa da escola pública associou a educação inclusiva com a inclusão dos alunos com deficiência. Não somente tenta incluí-los, como também tenta integrá-los para que se sintam parte do meio ambiente: "A inclusão não ocorre cem por cento, estão em sala de aula, existe aceitação por parte dos colegas, mas em alguns momentos ficam isolados com o professor de apoio, por conta das atividades que acabam não os integrando". O professor de Educação Física dessa escola já compreendeu a educação inclusiva como algo bom, desde que tenha apoio do poder público. Geralmente os "alunos de inclusão", os "alunos com problemas", são colocados em uma sala lotada, mas necessitam de mais atenção e apoio. Disse que a inclusão acontece, porém, a escola necessita de mais recursos para facilitar o trabalho dos professores (da sala de aula e o itinerante). A professora de Artes dessa mesma escola considerou que todos os alunos de inclusão são bem vistos. No entanto, percebeu diferença de convivência em relação aos novos alunos considerados de inclusão e os que frequentam a escola desde crianças, situação em que os demais aprendem a conviver com eles. Também relacionou os alunos considerados em situação de inclusão com os alunos com deficiência. 
Quanto à identificação de casos de bullying, a professora de Língua Portuguesa da escola privada relacionou os casos com a modernização das tecnologias. Com frequência, os alunos organizam grupos e tiram fotos de professores e de alunos em diferentes situações; fazem comentários das fotos com frases-padrão e, em seguida, divulgam nas redes sociais. Citou o caso de um aluno que apresentava hiperatividade e outras patologias fisiológicas que o faziam ser excluído da sala de aula a ponto de ninguém querer fazer atividades com ele. Mas o que chamava a atenção dessa professora de Língua Portuguesa era o fato de ele também reproduzir o bullying contra um menino que era negro, mas, contraditoriamente, ele também era negro: "não era moreno, era negro mesmo". Deduziu que o bullying, às vezes, é contagiante; a vítima, ao se acostumar com as ofensas, acaba por achar natural e reproduz a agressão. Explicou que esse caso foi bem sério, tiveram que chamar os pais, pois envolvia a questão do racismo: "Esse menino que também praticava bullying era conhecido pelos outros por meio do bullying. Por fim, ele acabou saindo da escola. Ele veio para a nossa escola com histórico de recusa de matrícula de outra instituição". Relatou também o caso de um aluno considerado homossexual que fazia teatro e que sofreu bullying devido às inúmeras "brincadeiras", manifestando, por muitas vezes, o desejo de sair da peça em que era protagonista. Contudo, essa professora conversou com ele a respeito da importância de ele se aceitar, pois, com a autoaceitação, o respeito dos outros viria.

O professor de Educação Física, por sua vez, expressou que: "Brincadeiras a gente presencia sempre, mas caracterizado como bullying eu não vi, a gente ouve falar. O que a gente vê é tirar sarro, fazer brincadeiras, mas não é tudo caracterizado de bullying". Já a professora de Artes dessa escola disse que presenciou poucos casos de bullying, e, quando isso acontecia, procurava conversar com o aluno. Nomeou o caso de um aluno considerado esquisito pelos colegas por ser muito fechado, embora tirasse boas notas, e de outra aluna que se sentia diferente por ter pais de religião distinta (católica e muçulmana) e as pessoas não a compreendiam. Essa professora destacou que: "É uma aluna mais responsável, e acaba gerando certo comportamento de bullying por se diferenciar dos outros".

A professora de Língua Portuguesa da escola pública afirmou que presenciou poucos casos de bullying em forma de brincadeira. Salientou que tais brincadeiras geralmente acontecem com as mesmas pessoas devido a algumas características. Se aparentemente o agredido dá ares de não se importar, percebeu que ele ficava incomodado com as piadas e os apelidos. Já o professor de Educação Física dessa escola disse que testemunha casos 
de bullying cotidianamente. Em relação ao bullying praticado entre os alunos, acontece entre eles mesmos, uns com os outros. Vem procurando esclarecerIhes que não se trata de um comportamento adequado, pois, no geral, eles não sabem o que pode acarretar, por exemplo, o ato de ofender alguém. Todavia, observa que os alunos também praticam bullying em relação ao professor; habitualmente, fazem comentários maldosos a respeito de um professor para outro ou para os próprios colegas. Já a professora de Artes dessa escola afirmou que não identificou casos de bullying, mas acrescentou: "grave, não". Tal qual a professora de Língua Portuguesa dessa escola, disse que já presenciou casos de brincadeiras que costumam ser verbais, de modo que, quando isso ocorria, procurava interferir.

No que diz respeito aos motivos do bullying e sobre as características dos agressores e dos agredidos, para a professora de Língua Portuguesa da escola privada, todo ser humano tem características físicas próprias, mas, contraditoriamente, por conta dessas diferenças, tem percebido que tem sido difícil a aceitação do outro, até mesmo devido à mídia, que impõe que você deva ter o corpo perfeito, deva ser "belo":

Na mídia, a inteligência tem sido deixada de lado dando lugar à esperteza. A mídia tem sido a maior responsável por incitar, grande parte dos seres humanos, a expor sua vida em uma hipotética vitrine, nessa, paulatinamente os indivíduos são moldados. O poder e a ambição agregados ao egoísmo têm deturpado os valores humanos, quem não entra nesses moldes é excluído, o que acaba sendo o estopim da violência verbal, até mesmo física.

Os alunos provocadores e que agridem usualmente ou têm poder aquisitivo maior que os demais, ou aparência física de ser mais forte e postura agressiva ou são considerados engraçados: "Todo círculo social tem o engraçado que faz as piadas, a pessoa acaba se aproveitando dessa posição para fazer o bullying. Os engraçados, tidos como os palhaços dos círculos sociais, incitam, pois, os colegas, que também querem ser assim, populares". Os agredidos sofrem devido à aparência física (negros; muito magros ou gordos demais; por conta do nariz e da orelha), à situação financeira (bolsistas) ou porque têm uma produção escolar um pouco mais lenta. Sublinhou que "[...] o professor influencia, involuntariamente, até por uma expressão facial; o aluno pergunta e o professor sem perceber faz aquela expressão, o resto da sala já percebe". Disse ainda que o"[...] aluno religioso vai ter comportamento diferente, resgata os valores humanos. Também, tem o preconceito com aquele que é ateu, é uma contradição". Já o professor de Educação Física dessa escola considerou que o bullying acontece por inveja e, também, por ser um tema de relevo na contemporaneidade. $\mathrm{O}$ aluno quer demonstrar poder $\mathrm{e}$ 
superioridade em relação aos outros colegas. Os que agridem têm algum problema em casa, a exemplo de presenciarem brigas e agressões entre os pais, bem como outros têm personalidade violenta ou são criados somente pela mãe e necessitam da figura paterna ou somente querem aparecer para a turma. Os agredidos são considerados alunos que podem também ter algum tipo de problema em casa, são tímidos, retraídos, provavelmente já sofreram algum tipo de problema na infância ou em outras escolas, e, ainda, há os alunos que não conseguem se expressar e se comunicar e acabam sofrendo com isso.

A professora de Artes dessa escola, no entanto, atribuiu a razão desse tipo de violência novamente à família e destacou o conflito entre quem não respeita o outro e pratica o bullying versus quem recebe (não se sente seguro e se reprime). Pontuou que o aluno que agride apresenta algum transtorno leve psicológico e, mesmo que tenha atribuído à família os motivos do bullying, sublinhou que cabe à escola enfatizar a importância do respeito ao outro. Em relação aos alunos agredidos, disse que: “Eles se sentem retraídos, humilhados e muitas vezes podem desencadear uma retaliação. Se não for sarado nesse período, com apoio psicológico, ele vai se tornar um agressor. Ele vai pensar 'Ninguém se importa comigo, por que eu vou me importar?"'.

Para a professora de Língua Portuguesa da escola pública, os motivos do bullying resultam da necessidade de autoafirmação do adolescente, de se sobrepor ao outro, de pensar que é melhor em relação a algum aspecto. Relaciona a atitude do agressor com alunos que têm histórico de problemas familiares e sociais devido ao ambiente em que vivem. Percebeu que ele (o agressor) sente necessidade de reproduzir comportamentos agressivos com o outro e, comumente, são alunos com comportamento agitado, com "aprendizagem dispersa". Já em relação aos que sofrem agressão, argumentou serem normalmente mais quietos e tímidos e, na sua maioria, são considerados bons alunos no quesito aprendizagem.

Para o professor de Educação Física dessa escola, os motivos também estão relacionados a fatores familiares, a exemplo de o filho presenciar em casa o pai falar mal da mãe e não ser orientado a respeito das consequências dessa atitude. O pai perdeu o poder perante o filho, bem como o filho perdeu o respeito pelo pai. Nesses casos, citou como exemplo o acesso às redes sociais:

[...] É difícil chamar o pai quando o Zezinho ofendeu o colega. Se fosse meu filho, eu levava para a delegacia, o meu filho e o outro. Entre os alunos, eles se xingam por qualquer coisa. Antes eu interferia em briga, hoje não. Quando é muito grave, levo para a coordenação. Se acontecer mais de uma vez, a coordenação deve chamar os pais. As regras da escola são frágeis, a escola 
não quer atrito com a comunidade. Já dei aula no estado e lá andava, porque praticavam o entendimento do juiz [...], e dava certo, mau comportamento limpavam banheiro, acredito ser boa essa lei.

Esse professor, quando questionado a respeito das características dos agressores e dos agredidos, esclareceu de antemão que o bairro onde a escola pública municipal está localizada é violento; destacou que "a briga está no sangue pelo bairro ser violento". Quanto aos alunos que agridem disse que:

Tem alunos com cara de santinho que estouram, na verdade se espelham no vizinho, os alunos se espel ham nos bandidos do bairro, não espel ham em coisas boas, admiram os bandidos. Se vangloriam quando a mãe está presa. O bairroé violento. Poucos têm a intenção de serem alguém, poucos se dão bem. Os alunos que se abrem comigo, direciono, dou conselhos. Precisam de oportunidade de cursos, qualificação. Celular é uma arma boa, mas não sabem usar. Tem escola que alunos não entram com celular. Aqui o professor tem que segurar.

No que diz respeito aos agredidos, disse que os alunos que sofrem bullying são os mesmos que praticam; carecem de boa estrutura familiar. Citou como exemplos o fato de o short curto não poder ser usado na escola, mas que a mãe de um aluno vem para o estabelecimento de ensino praticamente sem roupa, bem como alunas que precocemente são mães. Já a professora de Artes dessa escola afirmou que os motivos do bullying estão relacionados com o ato de revidar, isto é, esse tipo de brincadeira começa quando um aluno faz isso com o colega e este procura fazer o mesmo com ele. Disse que as pessoas devem procurar analisar/refletir sobre elas mesmas. Tal qual o professor de Educação Física, associa o agressor com alguém que advém de uma família desestruturada: são crianças que vão para a rua, quando suas mães saem cedo para trabalhar. As crianças fazem isso para chamar a atenção, como que sinalizando que alguma coisa está acontecendo na casa deles: "Quando pergunto [para o agressor] o porquê fez isso, ele diz: 'porque está acontecendo isso comigo'"'. Já os que sofrem agressão, como considera a professora de Língua Portuguesa dessa escola, são alunos mais tímidos.

Quanto ao fato de os alunos em situação de inclusão terem sido alvo de bullying tanto quanto os outros, a professora de Língua Portuguesa da escola privada entendeu que o bullying tem se tornado tão natural que a violência passou a ser equivalente entre todos os alunos. Estabeleceu-se um círculo vicioso, pois, quem é vítima, sofre, e acaba reproduzindo a agressão, a violência. Para o professor de Educação Física dessa escola, ainda que não tenha tido tanta experiência com os alunos em situação de inclusão, disse que são mais propensos a sofrerem bullying, pois têm mais dificuldade em 
se exprimir. Já a professora de Artes dessa escola disse que “Nessa escola não percebo isso. Tem uma brincadeirinha ou outra, mas nada agravante, mas acredito que deva existir o bullying". O professor de Educação Física da escola pública, por seu turno, relacionou os alunos considerados de inclusão com os alunos com deficiência e percebeu que não são alvos de bullying:

Possuo cinco alunos em situação, não sofrem bullying. Os alunos perguntamo que o outro tem, perguntam o porquê são tratados diferente, mas não praticam bullying. Fazem perguntas, mas não fazem alusão à deficiência, e sim por que eles são assim ou por que podem isso ou aquilo.

Para as professoras de Artes e de Língua Portuguesa da escola em referência, os alunos considerados em situação de inclusão não sofrem bullying. A primeira disse que, embora tenha percebido brincadeiras em relação aos outros alunos, nenhum colega faz brincadeiras com eles: "Não sei se porque já trabalham com os alunos o acolhimento dos alunos em inclusão ou porque tem o professor ao lado, o professor auxiliar". Já a segunda afirmou que: "Na minha percepção, os alunos de inclusão não são alvos de bullying, existe uma aceitação grande por parte dos alunos. Auxiliam o professor e os demais buscam cadeiras, coisas".

No que se refere ao que é necessário para combater esse tipo de violência na escola e o papel das autoridades, para a professora de Língua Portuguesa da escola privada, os professores devem trazer a questão para discussão e propiciar meios para que os alunos pensem, como realização de palestras e campanhas para a inclusão social. O professor de História, por exemplo, pode se reportar ao processo histórico da "evolução humana", aos direitos conquistados "[...] e que devemos acompanhar essa evolução e não regredir com a violência no comportamento humano. Enfim, pode-se trabalhar esse assunto por meio de conceitos da interdisciplinaridade". Quanto ao papel das autoridades, o bullying deve ser tratado tal qual o racismo, com penalidades rígidas: "Precisamos incutir nos seres humanos que o respeito é primordial, tão importante quanto o oxigênio. Se não quer ser humilhado, não pode humilhar. Isso deve ser tratado como um crime".

Para o professor de Educação Física dessa escola, o bullying está em proeminência e a escola exerce primordial papel para combatê-lo. Citou a realização de palestras e que, decerto, a escola deve punir os alunos que praticam esse tipo de violência. As autoridades devem dar mais apoio às escolas mediante a realização de palestras e de encontros sobre o assunto e, com isso, contribuiria para minimizá-lo. Já a professora de Artes da mesma escola mencionou alguns aspectos relacionados com sua própria experiência 
como mãe, ao citar como exemplo o fato de seu filho ter tido prejuízo no rendimento na escola, quando esteve em conflito com seu marido. A exclusão do seu filho de atividades na escola gerou insegurança e a não participação das comemorações escolares, o que interferiu no seu desempenho escolar: "Só quando mudamos o comportamento em casa, entramos para a igreja, o meu filho apresentou melhoras". A assistente social deveria trabalhar com a família, pois não adianta a escola veicular filmes com vistas à prevenção do bullying, por exemplo, se a criança em casa é vítima de violência, bem como se torna necessário envolver os familiares nas palestras proferidas nas escolas.

Quanto à questão em referência, a professora de Língua Portuguesa da escola pública afirmou que a punição, ainda que em alguns casos seja importante, seria a última alternativa, pois tanto quem agride e quem é agredido necessitam de auxílio:

O caminho é entender o porquê acontece, e, também, não atender só quem sofre, mas quem pratica, que tem algum problema, alguma necessidade. [...]. Começa na família, mas às vezes a família não percebe. A escola é omissa e encara como brincadeira - deve tomar um posicionamento e chamar os envolvidos para uma conversa. Apoio psicológico na escola seria adequado, muitas vezes é feito pelo professor e coordenador que não têm todo o preparo para lidar com algumas situações.

O professor de Educação Física dessa escola também compreendeu que a família é a base; sugeriu trabalho com os familiares, por meio de realização de palestras, distribuição de cartilhas. A disciplina deve ser rígida, pois os alunos estão sem limites; como os professores são formados dentro de certos modelos, quando se deparam com alunos da periferia, se defrontam com uma realidade totalmente diferente. As recomendações de ter disciplina, treinamento e bom comportamento advêm de sua própria experiência em projetos que vem desenvolvendo dentro de sua carga horária de trabalho na escola. Entende que quem comete bullying deveria ser penalizado na esfera criminal. Para isso, as leis deveriam ser mais severas, as pessoas deviam fazer cumprir as existentes, além de ser necessário dar mais autoridade à escola: "A escola deveria cumprir o regimento disciplinar, deveria ser mais rígido. $\mathrm{O}$ governo deve investir mais nos esportes nos bairros, nas escolas, pois teria uma melhora no comportamento dos jovens". A professora de Artes da mesma escola sinalizou a importância da educação do berço, de casa: "A família joga para escola, que a escola tem que resolver. A autoridade tinha que ser da família - o pai diz: 'não posso fazer isso com meu filho, porque a autoridade não permite (ECA, Estatuto da Criança e do Adolescente, e etc)". 
Diante do exposto, cabe refletirmos sobre os argumentos apresentados pelos entrevistados.

\section{REFLEXÕES ACERCA DOS ARGUMENTOS DOS PROFESSORES}

Dois dos professores da escola privada compreendem que o bullying implica atitude de superioridade de um sujeito sobre o outro, de o indivíduo manifestar força por intermédio de atitudes agressivas ou necessidade de contra-ataque com vistas a se defender. Isso, de certo modo, é explicado por Adorno (2000), ao mostrar com clareza a falência da nossa cultura, reflexo da sociedade contemporânea que vem se organizando de modo hierárquico e que, por meio da dominação social, elege os considerados melhores e piores. Assim, são mantidos os ciclos de reprodução da violência e de exclusão social (um tipo também de violência), que, nos termos de Silva, Freller, Alves e Saito (2017), encontram-se intensificados na escola, acompanhados de novos modos de hostilização fortemente caracterizados pelo elevado potencial de mobilização emocional. Outra professora dessa mesma escola, ao imputar a gênese do bullying ao núcleo familiar, desconsiderou que a família, a escola e outros espaços sociais promovem a mediação entre indivíduo e sociedade, e, devido ao domínio da totalidade social, as instituições não resistem ao que é dado e reproduzem o que acontece na realidade estabelecida. Ao caracterizar a geração atual como "sai pra lá", levou em conta o caráter histórico que permeia a relação entre os homens, mas não percebeu que tal geração é fruto da razão instrumental infiltrada no nosso cotidiano.

Se ainda há equívocos no ambiente escolar em relação ao bullying, os professores da escola pública consideraram que esse fenômeno consiste em atitudes verbais ou físicas que agridem ou discriminam o outro e que, geralmente, ocorrem em grupos de crianças e adolescentes em que os alunos não percebem a gravidade do problema, somente os professores. Como explica Adorno:

No estereótipo de "estar fora da realidade" fundem-se os traços infantis de alguns professores com os traços infantis de muitos estudantes [...]. Na medida em que se adaptam de modo mais exitoso ao princípio da realidade do que pode fazer o professor, que continuamente precisa anunciar e dar corpo a ideais de superego, acreditam compensar aquilo que acreditam ser o que lhes faz falta, isto é, não constituem sujeitos independentes (ADORNO, 2000, p. 110). 
Nesse excerto, há claramente crítica ao próprio processo educativo que até hoje em dia malogrou em nossa cultura. A violência, seja física, seja psíquica, vem sendo considerada como brincadeira e, com isso, os sujeitos vão se habituando ao desrespeito mútuo e acabam por reproduzir a violência. $O$ professor da escola privada não levou em conta que brincadeiras no ambiente escolar podem significar atitudes agressivas em relação ao outro, fato esse confirmado por uma professora da escola pública, ao dizer que o bullying em forma de brincadeira geralmente ocorre com as mesmas pessoas por conta de algumas características próprias que não são aceitas pelo agressor. Igualmente, uma das professoras dessa última escola disse que já presenciou casos de brincadeiras que costumam ser verbais e, quando isso acontece, procura interferir. Como esclarecem Cerqueira, Santos e Silva:

O divórcio entre o pensar e o sentir aciona a economia do esforço intelectual em que o pensamento opera, por meio de tickets do tipo: se negro, então marginal; se deficiente, então incapaz. Nesses casos, ocorre uma espécie de equivalência funcional precipitada, entre situações distintas e sem mediações pela consciência (CERQUEIRA; SANTOS; SILVA, 2013, p. 38).

Outra professora dessa mesma escola já disse que os alunos tendem a adoecer na proporção que guardam para si o constrangimento por que passam. Para Leão (2010), isso não somente faz acender ainda mais a violência nas escolas, como também normaliza o sofrimento da vítima: "As vítimas, muitas vezes, sofrem caladas, carregando o trauma das situações de constrangimento que vivenciaram para o resto de suas vidas, gerando consequências na fase adulta como problemas de interação e relacionamento com outros sujeitos" (LEÃO, 2010, p. 123). Outro docente, da escola privada, ao responsabilizar a escola pela educação inclusiva - concebida como atendimento aos alunos com necessidades especiais - tem uma visão restrita sobre a inclusão, tal qual uma das professoras dessa escola, e, em razão disso, ambos não refletem acerca das questões políticas envolvidas nesse processo, a exemplo da responsabilidade do Estado no processo de inclusão. Pois, como afirma Adorno (2000, p. 137): “Seria preciso tratar criticamente um conceito tão respeitável como o da razão de Estado, para citar apenas um modelo: na medida em que colocamos o direito do Estado acima do de seus integrantes, o terror já passa a estar potencialmente presente".

O professor da escola pública compreendeu a importância da educação inclusiva - entendida por todos os professores dessa escola como atendimento aos alunos com deficiência, com problemas --, desde que contem com o apoio do poder público. Uma das professoras dessa escola já 
chamou a atenção para a importância da inclusão e da integração, mas, na realidade, não difere esses dois conceitos e trata-os como sinônimos. Já a outra professora teceu críticas em relação à sala de aula lotada para atender os alunos considerados em situação de inclusão e ressaltou a importância de recursos públicos para facilitar o trabalho tanto do professor responsável pela sala de aula quanto do professor itinerante. Essa questão nos leva ao que elucidou Crochík, em relação ao professor auxiliar:

Se a presença de um professor auxiliar é importante para todos os alunos, quando se destina basicamente aos considerados em situação de inclusão tende a isolá-los, e esse é outro mecanismo que indica manutenção da segregação dos alunos considerados em situação de inclusão, mesmo estando em sala de aula. Não se deve negar que em alguns momentos esse professor de apoio é necessário para o aprendizado dos alunos considerados em situação de inclusão, e mesmo que eles sejam seus principais destinatários, mas isso não deveria significar que se tornasse, para esses alunos, o professor titular (CROCHÍK, 2013, p. 19).

A partir das contribuições de Mantoan em Inclusão escolar: o que é? por quê? como fazer?, os termos "integração" $\mathrm{e}$ "inclusão" fundamentam-se em diferentes abordagens teórico-metodológicas. O primeiro tem como base o princípio de normalização e consiste em uma concepção parcial de inserção dos alunos na medida em que a escola não modifica em sua totalidade, e os estudantes têm de se modificar para se adaptarem às suas exigências, que não se diferenciam dos interesses da ideologia da realidade estabelecida, regulada pela lógica da equivalência. A inclusão, contraditoriamente, analisa não somente o conceito de integração, como também a estruturação e as políticas da educação especial e regular, de forma que as necessidades de todos os alunos são levadas em conta independentemente de terem ou não dificuldades de aprender e todos devem estar inseridos no ambiente escolar regular (MENESES; PEDROSSIAN, 2013).

Uma das professoras da escola privada identificou casos de bullying na escola relacionados com a homofobia e o racismo, chamando a atenção para a relação vítima-praticante e para o uso inadequado das redes sociais na prática do cyberbullying contra alunos e professores. Outro aspecto que mereceu destaque no discurso dessa professora foi a exclusão social provocada por escolas que se recusam a receber alunos com histórico de provocadores, bem como atitudes preconceituosas por parte dela própria ao se referir ao aluno negro. Não é fortuito que, na pesquisa empírica realizada com professores, Silva, Freller, Alves e Saito (2017) detectaram que professores consideram o ambiente escolar como elemento constitutivo do bullying e reconhecem que 
determinadas práticas de seus pares poderiam reforçá-lo. Ao analisarmos o que disse outra professora da escola privada, a homogeneização vem se sobrepondo à diferenciação, interferindo nos direitos de uma minoria religiosa, que, nos termos de Crochík (2016), seria o de ter uma vida em seu grupo religioso e, também, poder conviver com todos, desde que não fossem prejudiciais à comunidade.

Ao direcionarmos para os motivos do bullying e para as características dos agressores e dos agredidos, uma das professoras da escola privada apontou a atitude do professor como fomento desse tipo de violência e sublinhou como características dos agredidos aspectos físicos e comportamentais, socioeconômicos, religiosos e intelectuais, o que confirmou, de acordo com Crochík ( 2016, p. 9), que "[...] o bullying tem como base sobretudo o desejo de submissão do outro à vontade do autor da agressão". Uma das professoras da escola pública já salientou que a necessidade de autoafirmação do adolescente (de pensar que é melhor em relação ao outro) encontra-se na base do desejo de se sobrepor ao outro. Relacionou a atitude do agressor com o ambiente em que vive e por ser proveniente de famílias com problemas. Mas, ao caracterizar o agressor (como aluno de aprendizagem dispersa, de comportamento agitado) e a vítima (como aluno tímido, quieto, que tira boas notas), aproximou-se do que afirmou o professor da escola privada. Este compreendeu o bullying como fenômeno individual e natural e não como fenômeno, também, social. Assim, responsabilizou o indivíduo pela prática desse tipo de violência. Não à toa esse professor identificou que esse tipo de violência comumente vem ocorrendo por conta de sentimentos de inveja, por necessidade de demonstrar poder e superioridade em relação ao outro, por problemas familiares e de personalidade. Assim, acabou por assumir um discurso em que os fatos aparentes devam ser compreendidos por si mesmos.

A questão familiar e a violência do bairro onde a escola pública está localizada foram apontadas como motivos do bullying pelo professor dessa escola. Nesse sentido, Souza (2013) elucida que as consequências do modelo de sociedade cujas bases vêm provocando violência em grande escala, desigualdades sociais, formas de exclusão social, e que afrontam os direitos humanos dos grupos considerados como minorias, demandam a necessidade de elaboração do pensamento crítico comprometido política e eticamente com a reflexão sobre os elementos que vêm propiciando a degradação dos direitos humanos. Percebemos, também, que a questão de o agredido e o agressor necessitarem de tratamento foi evidente na fala de uma das professoras da escola privada. Todavia, à medida que o psicologismo e a percepção naturalizada da realidade se impõem, corre-se o risco de perpetuar as condições objetivas adaptativas. Pois, segundo Adorno: 
Pelo fato de o processo de adaptação ser tão desmesuradamente forçado [...], eles precisam impor a adaptação a si mesmos de um modo dolorido, exagerando o realismo em relação a si mesmo [...]. A crítica desse realismo supervalorizado parece-me ser uma das tarefas educacionais mais decisivas, a ser implementada, entretanto, já na primeira infância (ADORNO, 2000, p. 145).

Ainda que o nível de compreensão do bullying interfira na qualidade das intervenções realizadas, o que corrobora a hipótese de Silva, Freller, Alves e Saito (2017), houve unanimidade por parte dos professores da escola privada de que a sociedade atual vem sustentando a violência e que os mais vulneráveis em relação ao bullying são os alunos considerados em situação de inclusão. Se, de um lado, os professores dessa escola reconhecem que a violência tem sua gênese nas relações sociais, de outro, se valem do determinismo mecanicista, ao resguardarem as instituições educacionais como apregoadores do domínio dos considerados frágeis. Para os professores da escola pública, os alunos considerados em situação de inclusão são geralmente relacionados com os alunos com deficiência, mas não são alvo de bullying - existe uma grande aceitação por parte desses alunos; os colegas somente questionam o porquê de eles serem tratados de forma diferente e, provavelmente, isso vem ocorrendo devido a uma política de acolhimento e da presença do professor de apoio ou itinerante que acompanha o aluno considerado em situação de inclusão em sala de aula. A questão também que se apresenta é que, segundo Souza:

[...] os currículos possuem uma orientação homogeneizadora, que não considera a diferença como algo peculiar ao ser humano, logo, concepções epistemológicas de ensino e aprendizagem são veiculadas nos percursos formativos, sem dar visibilidade aos ritmos, estilos e modos de aprender subjacentes à diversidade dos estudantes (SOUZA, 2013, p. 92)..

Uma das professoras da escola privada, embora tenha reclamado acerca da participação dos pais no combate ao bullying, mostrou o poder da mídia e imputou a responsabilidade aos professores no que se refere ao desenvolvimento de ações inclusivas no ambiente escolar. Priorizou a discussão e a reflexão como estratégias de esclarecimento; a colaboração interdisciplinar, a tolerância e a compreensão como posturas esperadas do educador. Ao expor sobre o papel das autoridades, a atitude tendeu para a perspectiva de punir o agressor. Porém, a questão da punição foi algo contraposto por uma das professoras da escola pública, pois entende ser esta a última opção, visto que tanto quem agride quanto quem é agredido necessitam de auxílio psicológico. Sugeriu a necessidade de haver 
envolvimento dos familiares, professores, coordenadores e de profissionais da saúde. Todavia, o professor dessa escola não só recomendou o envolvimento dos familiares no combate ao bullying, como também pontuou a necessidade de disciplina rígida e salientou que quem comete esse tipo de violência deveria ser penalizado no âmbito criminal. Apontou a necessidade de se direcionar a atenção para: formação dos professores; maior autoridade por parte da escola; maior investimento do governo nos esportes como forma de melhorar o comportamento dos jovens. Observamos, em relação a essa última recomendação, a existência da dupla hierarquia na esfera escolar, nos termos de Adorno (2000).

Dois dos professores da escola privada chamaram a atenção para a importância dos professores no combate ao bullying; se a primeira citou a necessidade de incutir respeito entre as pessoas e o uso de penalidades rígidas, quando o outro é humilhado, o segundo, além de ser também a favor da punição, disse que as autoridades deveriam dar mais apoio às escolas mediante a realização de palestras e de encontros sobre o assunto e, com isso, contribuiria para minimizá-lo. Já outra professora destacou a importância de mudanças de atitudes na família e o envolvimento da assistente social. Por seu lado, uma das professoras da escola pública considerou a punição como última alternativa; dois já entenderam ser a família a base, ainda que um deles tenha chamado a atenção para a necessidade de adoção de disciplina rígida e maior autoridade à escola, bem como foi a favor de criação de leis mais severas e de penalização criminal no combate ao bullying. Após essas reflexões, apresentamos nossas considerações sobre o tema em questão.

\section{BREVES CONSIDERAÇÕES}

A análise das entrevistas com os seis professores possibilitou uma conclusão provisória, devido à abrangência da pesquisa empírica em andamento, cabendo esclarecer que essa apreciação será articulada com outras análises do estudo como um todo. Se partirmos do pressuposto de que, para Adorno (1995), o indivíduo singular deve a perspectiva de sua existência ao todo social e que unicamente a tomada de consciência do social propicia ao conhecimento a objetividade que ele perde durante o tempo em que obedece às forças sociais que o dominam, sem refletir sobre elas, podemos dizer que os sujeitos da pesquisa, ainda que apontem aspectos importantes relacionados à relação professor-aluno, ao poder da mídia e das redes sociais na incitação do bullying, não conseguem desenvolver suas atividades de modo autônomo e com autodeterminação. 
Todavia, o estudo em questão permitiu momentos de autorreflexão dos professores em relação ao desenvolvimento de suas atividades com os alunos e ao bullying. Se o aluno sinaliza se encontrar regredido quando se trata da questão do bullying, isto é, os estereótipos e os predicados passam a definir os objetos, mas sem relação com os objetos, a exemplo do agressor não saber sequer o que agride, o bullying, portanto, implica uma violência gratuita, uma ação de destruição do outro. Desse modo, convivemos com os limites da democracia na sociedade atual que "produz o que é antidemocrático a partir de suas próprias instituições formais" (SILVA; FRELLER; ALVES; SAITO, 2017, p. 44) e também cerceia a constituição da individualidade. Isto é, o indivíduo - e aqui podemos considerar todos os que fazem parte dos ambientes escolar, familiar e social -, ao ser cerceado no seu processo de formação, é impedido de diferenciar-se e de abrir-se às disposições psíquicas como o medo e a fragilidade, fundamentais à convivência pacífica com o diferenciado e ao exercício da autonomia, sem qual é impossível a democracia (SILVA; FRELLER; ALVES; SAITO, 2017). Como destacam os autores:

Se, tal como definido pelas políticas públicas de educação vigentes no Brasil, a escola visa à formação de sujeitos autônomos, não se pode ignorar que a esfera da consciência é central para a compreensão das contradições que apresenta atualmente. É somente mediante a consciência que se poderá perceber e enfrentar a constante estimulação social à violência e à frieza expressadas de maneira direta no bullying e disseminadas nas relações sociais em geral (SILVA; FRELLER; ALVES; SAITO, 2017, p. 46).

Segundo Giordano, Oliveira e Nazareth (apud CROCHÍK, 2016), as diferenças provocam estranhamento, a ponto de estar também presente em alguns discursos dos professores o trato dos alunos considerados em situação de inclusão de acordo com os padrões de "normalidade" estabelecidos, sem considerar as diferenças de cada estudante. Concordamos com as autoras que não podemos deixar de refletir sobre a dominação social que vem interferindo demasiadamente no nosso processo formativo, por este não vir associado com críticas às contradições presentes na sociedade. Assim, os valores institucionalizados acabam por prevalecer nos conhecimentos estabelecidos mediante meios moduladores de um pensamento controlado por regras e harmonioso (GIORDANO, OLIVEIRA, NAZARETH, apud CROCHÍK 2016), de modo que, não por acaso, três dos entrevistados apontaram a punição como meio de combater o bullying. Também não estamos de acordo com que o bullying e outros tipos de violência possam ser combatidos por meio do incentivo à interdisciplinaridade, conforme argumentado por uma das professoras, mas pelo confronto de disciplinas. Pois, para Adorno (1986), a interdisciplinaridade, ao ter primazia pelo conhecimento e não pelo objeto 
de estudo, cumpre funções ideológicas, tal qual ocorreu neste estudo em que a gênese do bullying se relacionou com explicações centradas no primado do sujeito e não na relação sujeito-objeto.

Embora o termo bullying tenha seu uso recente, a violência que o caracteriza faz parte do processo histórico e se encontra presente no processo de (de)formação do professor, que não está imune também ao fenômeno do preconceito. Não por acaso, Adorno (2000) contrapõe-se à força cega de todos os coletivos mediante o fortalecimento da resistência, do esclarecimento em relação à coletivização, o que implica dizer que o combate ao bullying e a outros tipos de violência deve ocorrer no processo de formação do indivíduo, com início na educação infantil e, portanto, não se limita aos familiares, embora não se possa negligenciar a responsabilidade da família no processo de formação do indivíduo, que, certamente, participa da produção desse tipo de violência. Mas reduzir o bullying à família e à escola nos leva a equívocos sobre como enfrentá-lo. Destarte, não se trata de defendermos uma educação autoritária que seja mero instrumento disciplinador de condutas por intermédio da repreensão, meio este que vem predominando durante muitos anos de forma explícita mediante castigos físicos e morais, e que vem persistindo também hoje de maneira disfarçada mediante repressão psicológica que gera violência simbólica, a exemplo de se tratar uma agressão como brincadeira. Segundo Silva, Freller, Alves e Saito (2017), o bullying não é reflexo de problemas psicológicos próprios da esfera pedagógica, porém, compreende dimensões institucionais relacionadas à escola e ao conjunto das organizações que acondicionam a vida social, princípios psicodinâmicos presentes nas relações grupais e familiares, e ao todo social que se concretiza em cada elemento privado que o constitui. Com isso, exerce grande pressão sobre as instituições sociais e os indivíduos.

Por fim, para os autores da Teoria Crítica, os mesmos elementos que influenciaram os grandes conflitos do passado ainda vêm perdurando na sociedade atual e devem ser combatidos prontamente. Um dos meios para isso consiste em propiciarmos uma educação que se direcione para formar cidadãos conscientes de seus direitos e deveres e que respeitem as diferenças com vistas ao bem comum que, sem dúvida, não pode ser apartado do sentido de humanidade nas relações sociais e dos valores democráticos cotidianamente suscitados. Para isso, é preciso que estimulemos a reflexão sobre o tema em questão, suplantemos a mera adaptação, que possamos ter consciência esclarecida daquilo que fazemos e resistamos diante do poder da realidade estabelecida rumo à mudança social que inclua a todos. 
NOTES ONTHE INTERVIEWS WITH TEACHERS OF A PRIVATE SCHOOL AND ANOTHER PUBLIC OF THE MUNICIPALITY OF CAMPO GRANDE - MS

AвSTRACT: In this article, we present data from the interviews conducted with six professors (three from a private school and three from a public school) from the municipality of Campo Grande - MS, who teach Portuguese, Physical Education and Arts, according to a constant script in the project School Violence: discrimination, bullying and responsibility (CROCHÍK, 2014), with an increase of two questions. We explain teachers' understanding of bullying and inclusive education; identification and reasons for bullying in school; characteristics of aggressors and aggressors; students considered to be in inclusion are bullied as much as the others; what is needed to combat this type of violence at school and the role of the authorities. We conclude that it is appropriate to provide an education that is directed to educate citizens who are aware of their rights and duties, who respect the differences and reflect on the democratic values that are daily raised for the common good.

KEYWORDS: Bullying. Inclusive education. Discrimination. Very common.

NOTAS SOBRE LAS ENTREVISTAS CON PROFESORES DE UNA ESCUELA PRIVADA Y OTRA PÚBLICA DEL MUNICIPIO DE CAMPO GRANDE - MS

RESUMEN: En este artículo se presentan los datos de las entrevistas con seis maestros (tres de una escuela privada y pública) de tres Campo Grande - MS, que enseñan materias de Lengua Portuguesa, Educación Física y Artes, de acuerdo con la secuencia de comandos en el Proyecto de la violencia escolar: discriminación, bullying y responsabilidad (CROCHÍK, 2014), con el añadido de dos cuestiones. Expone la comprensión de los profesores en relación al bullying ya la educación inclusiva; identificación y motivos del bullying en la escuela; características de los agresores y de los agredidos; los alumnos considerados en situación de inclusión son objeto de bullying tanto como los demás; lo que es necesario para combatir ese tipo de violencia en la escuela y el papel de las autoridades. Concluimos que cabe propiciar una educación que se dirija hacia formar ciudadanos conscientes de sus derechos y deberes, que respeten las diferencias y reflejen sobre los valores democráticos cotidianamente suscitados con miras al bien común.

Palabras clave: Bullying. Educación inclusiva. Discriminación. Bien común.

\section{REFERÊNCIAS}

ADORNO, T.W. Acerca de la relación entre sociología y psicología. In: JENSEN, H. Teoria crítica del sujeto. Buenos Aires: Siglo XXI, 1986. p. 36-83. 
. Sobre sujeito e objeto. In: Palavras e sinais: modelos críticos 2. Trad. Maria Helena Ruschel. Petrópolis, RJ: Vozes, 1995. p. 181-201.

.Educação e emancipação. 2 ed. Rio de Janeiro: Paz e Terra, 2000.

CERQUEIRA, A. V. M; SANTOS, J. B.; SILVA, L. M. Educação e emancipação: considerações sobre o conceito de formação em Theodor W. Adorno. In: SILVA, L. M.;

SOUZA, L. R. (Org.) Estudos sobre formação e educação inclusiva. Salvador: EDUNEB, 2013. p. 31-53.

CROCHÍK, J. L. Uma pesquisa sobre educação inclusiva. In: SILVA, L. M.; SOUZA, L. R. Estudos sobre formação e educação inclusiva. Salvador: EDUNEB, 2013. p. 15-29.

.Projeto Violência escolar: discriminação, bullying e responsabilidade. São Paulo: Universidade de São Paulo, 2014.

. Introdução. In: CROCHÍK, J. L. Educação inclusiva. Algumas pesquisas. São Paulo: Novas Edições Acadêmicas, 2016. p. 05-30.

GIORDANO, R.; OLIVEIRA, J. V.; NAZARETH, L. J. S. Educação, in(ex)clusão social e preconceito nas escolas do Pará. In: CROCHÍK, J. L. Educação inclusiva. Algumas pesquisas. São Paulo: Novas Edições Acadêmicas, 2006. p. 153-202.

LEÃO, L. G. R. O fenômeno bullying no ambiente escolar. Revista FACEVV, Vila Velha, n. 4, p. 119-135, 2010.

MENESES, B.; PEDROSSIAN, D. R. S. A ideologia da integração na educação inclusiva. In: SILVA, L. M.; SOUZA, L. R. (Org.) Estudos sobre formação e educação inclusiva. Salvador: EDUNEB, 2013. p. 115-132.

SILVA, L. M.; SANTOS, J. B.; DOURADO, J. Inclusão e preconceito: um olhar sobre alunos com deficiência em escolas de Salvador (BA). In: CROCHÍK, J. L. Educação inclusiva. Algumas pesquisas. São Paulo: Novas Edições Acadêmicas, 2006. p. 31-71.

SILVA, P. F.; FRELLER, C. C.; ALVES, L. S. L. SAITO, G. K. Limites da consciência de professores a respeito dos processos de produção e redução do bullying. Psicologia USP, $v$. 28, n. 1, p. 44-56, 2017.

SOUZA, L. R. Discriminação de estudantes com deficiência: reflexões sobre o preconceito e a educação inclusiva. In. SILVA, L. M.; SOUZA, L. R. (Org.) Estudos sobre formação e educação inclusiva. Salvador: EDUNEB, 2013. p. 77- 98.

Branca Maria de Meneses: Graduação em Psicologia - Faculdades Unidas Católicas de Mato Grosso (1979), mestrado em Educação pela Universidade Federal de Mato Grosso do Sul (1995) e doutorado em Psicologia (Psicologia Social) pela Pontifícia Universidade Católica de São Paulo (2007). Atualmente é professora com dedicação exclusiva na Universidade Federal de Mato Grosso do Sul.

E-mail: brancameneses@yahoo.com.br. 
Dulce Regina dos Santos Pedrossian: Possui graduação em Psicologia - Faculdades Unidas Católicas de Mato Grosso (1979), mestrado em Educação pela Universidade Católica Dom Bosco (1998) e doutorado em Psicologia (Psicologia Social) pela Pontifícia Universidade Católica de São Paulo (2005). Psicóloga e professora colaboradora aposentada do Centro de Ciências Humanas e Sociais da Universidade Federal de Mato Grosso do Sul - UFMS. Graduação em Filosofia pela Universidade Católica Dom Bosco (2015). Tem experiência na área de Psicologia, com ênfase em Psicologia Social, atuando principalmente nos seguintes temas: relação entre indivíduo, cultura e sociedade por meio da teoria crítica e da teoria freudiana.

E-mail:drsp@terra.com.br

FernandA RITA LeVANDOSKI: Possui graduação em Psicologia pela Universidade Federal de Mato Grosso do Sul, mestrado em Psicologia pela Universidade Federal de Mato Grosso do Sul, graduação em Pedagogia pela Faculdade Integrada de Paranaíba - FIPAR. Psicóloga concursada, atuando no CAPS I da cidade de São Gabriel do Oeste/MS.

E.mail: <fer_doski@hotmail.com>. 